\title{
Testing CPUE-derived spatial occupancy as an indicator for stock abundance: application to deep-sea stocks
}

\author{
Verena M. TrenKeL ${ }^{1, a}$, Jonathan A. BeEchAM ${ }^{2}$, Julia L. BlanchARD ${ }^{3}$, Charles T. T. EdWARds ${ }^{3}$ \\ and Pascal LORANCE ${ }^{1}$ \\ 1 Ifremer, rue de l'île d'Yeu, BP 21105, 44311 Nantes Cedex 3, France \\ 2 CEFAS Lowestoft Laboratory, Pakefield Road, Lowestoft, NR33 0HT, UK \\ 3 Division of Biology, Imperial College London, Silwood Park, Ascot, SL5 7PY, UK
}

Received 12 February 2013; Accepted 22 July 2013

\begin{abstract}
The status of an exploited population is ideally determined by monitoring changes in abundance and distributional range and pattern over time. Area of occupancy is a measure of the current distribution. Unfortunately, for many populations, scientific abundance and distribution information is not readily available. To evaluate the reliability of commercial fishing data for deriving occupancy indicators that could serve as proxies for stock abundance, we investigated four questions: 1) Occupancy changes with stock biomass, but is this change strong enough to make occupancy a sensitive indicator of population biomass? 2) Fishing boats follow fish, but when does such activity alter the positive macroecological relationship between occupancy and abundance? 3) When does the activity of pursuing fish adversely affect occupancy estimates derived from catch and effort data? 4) How does uncertainty in fishing effort data affect occupancy estimates? Spatial simulations mimicking the dynamics of four deep-water fish species showed that biomass-occupancy relationships can be weak. Fishers following fish can modify the spatial distribution of target species, even reversing the sign of the biomass-occupancy relationship in certain cases, and can affect the reliability of occupancy indicators, which can also be impaired by error in effort data. Using commercial catch and effort data and abundance indices for deep-sea fish populations to the west of the British Isles it was found that only for roundnose grenadier might occupancy provide insights into biomass changes. In conclusion, care should be taken when using occupancy for evaluating range changes in cases where fishing might have modified spatial distributions, uncertain commercial data are used or when the abundance-occupancy relationship is too flat.
\end{abstract}

Keywords: Catch per unit effort / Spatial patterns / Macroecology / Fisheries management / Marine Strategy Framework Directive / MSFD

\section{Introduction}

The overall status of an exploited population is ideally determined by monitoring changes in abundance and distribution over time. For many populations, abundance and distribution information are not readily available because distributions span large spatial scales and it is difficult and costly to adequately sample their habitats. This is the case for many deepsea fish populations, which are not well sampled by surveys or which rely on commercial data (such as catch and effort data from fisheries) because they lack survey data altogether (Large et al. 2013). In light of multiple impacts from overexploitation, climate change and habitat degradation, better methods are needed to reliably evaluate the status and vulnerability of such populations from the data that are available or from those obtainable in cost-effective ways. Evaluating the status of all exploited marine species has become mandatory

a Corresponding author: verena.trenkel@ifremer. fr in Europe with the introduction of the Marine Strategy Framework Directive (MSFD) (EC 2008).

The distribution area of many populations is positively related to abundance such that, at large population size, more habitat space is occupied and abundance-occupancy relationships form well known macroecological patterns. Macroecology studies relationships between body mass, population density and the size and shape of geographic distributions (Brown and Maurer 1989). Various theories have been put forward to explain abundance-occupancy relationships including: density-dependent habitat selection (ideal free distribution theory), local vital rates (birth and death), and range position, see review in Gaston et al. (2000). Furthermore, in the absence of abundance information, indicators of spatial distribution have been proposed as a direct measure of population status (EC 2010). For example, area of occupancy of species and the larger geographical extent of occupancy, which can include uninhabited patches, have been used to assess threat to species as part of the IUCN red-listing process (Gaston and Fuller 2009). 
Different methods have been explored to measure occupancy for marine and terrestrial animal populations, such as the proportion of occupied sites within the wider distribution range or the area above a threshold density, see review in Gaston and Fuller (2009).

In fisheries ecology, theory and data on abundance-area relationships have been used to study the contraction of marine animal populations, whether these correspond to suitable habitats at low density or the consequences of management (MacCall 1990; Swain and Sinclair 1994; Fisher and Frank 2004; Blanchard et al. 2005; Frisk et al. 2011). However, stocks do not necessarily contract to the most suitable habitat (Shackell et al. 2005). A major problem arises when populations contract into smaller areas at low abundance because local density may not decrease, thus increasing the efficiency with which individuals can be caught.

Fishers themselves have been studied for their spatial behaviour and have been shown to move between areas to equalize catch rates (Gillis et al. 1993), although vessel movements can be constrained by management (Murawski et al. 2005), economic factors (Gillis and van der Lee 2012) or competition (Gillis and Peterman 1998). Dynamic coupling between the spatial distribution of fish and fishers might make fish populations increasingly vulnerable to overexploitation and lead to catch per unit effort (CPUE) not being proportional to stock abundance, e.g., Gillis and Peterman (1998).

The use of occupancy indicators for management relies on the data providing an unbiased picture of the underlying population distribution. This can be expected for random sampling designs or spatial grids with random starting points if the sampling intensity is sufficient and the spatial grid is fine enough. If, however, the spatial distribution of the data collection points follows the abundance of the population, i.e., sample locations are denser in higher density areas, a situation referred to as preferential sampling arises, with the consequence that classical spatial statistical analyses are biased (Diggle and Menezes 2010; Gelfand et al. 2012). Commercial catch data generally exhibit preferential sampling characteristics as fishers target species with heterogeneous spatial distributions. As a consequence, estimated occupancy might be a biased measure of true occupancy.

The French mixed-species deep-water trawl fishery to the west of the British Isles has three main target species: blue ling (Molva dypterygia), black scabbardfish (Aphanopus carbo), and roundnose grenadier (Coryphaenoides rupestris), as well as a bycatch of deep-water sharks, Centrophorus squamosus and Centroscymnus coelolepis (Lorance and Dupouy 2001). These species have different, but overlapping, habitat (depth) preferences (Ehrich 1983) and life history parameters that make them more or less susceptible to exploitation. Further, most of the data available for this fishery are commercial catch and effort data. Statistical modelling of a subset of haulby-haul landings data from the same fishery revealed seasonal and spatial, but also vessel effects on blue ling catches (Lorance et al. 2010; Augustin et al. 2013). Only the spatial effects will be considered here.

To evaluate whether commercial catch and effort data from the deep-water trawl fishery could be used to derive occupancy as a measure of stock dynamics to provide information for management, we asked four questions: (1) are occupancy changes strong enough to make this a sensitive indicator of population biomass? (2) When does spatial targeting by fishing boats alter the positive macroecological relationship between occupancy and abundance? (3) When does the activity of pursuing fish adversely affect occupancy indicator estimates derived from catch and effort data? (4) How does uncertainty in fishing effort data affect occupancy indicator estimates? We addressed these questions using spatially explicit multi-species simulations, considering technical interactions of the three target species of the deep-water fishery and deep-water sharks as a bycatch group. Finally, we use the insight gained from the simulations to interpret occupancy indicators calculated for the French deep-water trawl fishery to the west of the British Isles.

\section{Materials and methods}

\subsection{Occupancy}

Occupancy was estimated as the proportion of the total occupied area, $\mathrm{O}_{x}$, in which $x$-percent of the quantity of CPUE were found. It was obtained by ordering the spatial data units (here ICES statistical rectangles) from the largest to the smallest CPUE value and stopping when $x$-percent of the total sum of CPUE was reached. Dividing the sum of the surface areas of these units by the total area provides an estimate of $\mathrm{O}_{x}$. To increase precision, a uniform distribution of CPUE within each spatial unit was assumed. The subscript $x$ in $\mathrm{O}_{x}$ was omitted in the following simulation study as it was always $75 \%$.

\subsection{Spatial simulations}

Spatially-explicit simulations on a grid were used to evaluate the effects of a fishery targeting species spatial distributions, and catch- and effort-derived occupancy estimates (Fig. 1a). For this, the spatio-temporal population dynamics of four species intended to mimic the case study species black scabbardfish, blue ling, roundnose grenadier and deepwater sharks were simulated separately using surplus production models, with growth and carrying capacity varying spatially according to habitat preferences. The spatial distribution of fishing effort and the resulting species catches were then simulated as a function of the biomass of the target species and assuming that the fishing effort distribution could also be described by an ideal free distribution. Only technical interactions caused by species present in the same grid cell being fished together were taken into account. Biological interactions were ignored as they are weak among the case study species: these are predators of large and mobile preys, except for roundnose grenadier, which feeds primarily on pelagic crustaceans and other small preys (Mauchline and Gordon 1984; Hutton et al. 2004). Small blue ling and black scabbardfish, of $<70 \mathrm{~cm}$, do not occur in the study area, so that only small roundnose grenadier is susceptible to be preyed upon by the other species. The contribution of the three species to the diet of deep-water sharks is minor (Mauchline and Gordon 1983). All simulations of population and fisheries dynamics were deterministic. A stochastic element was introduced for simulation runs in which fishing effort was assumed to have been observed with error (see below). 

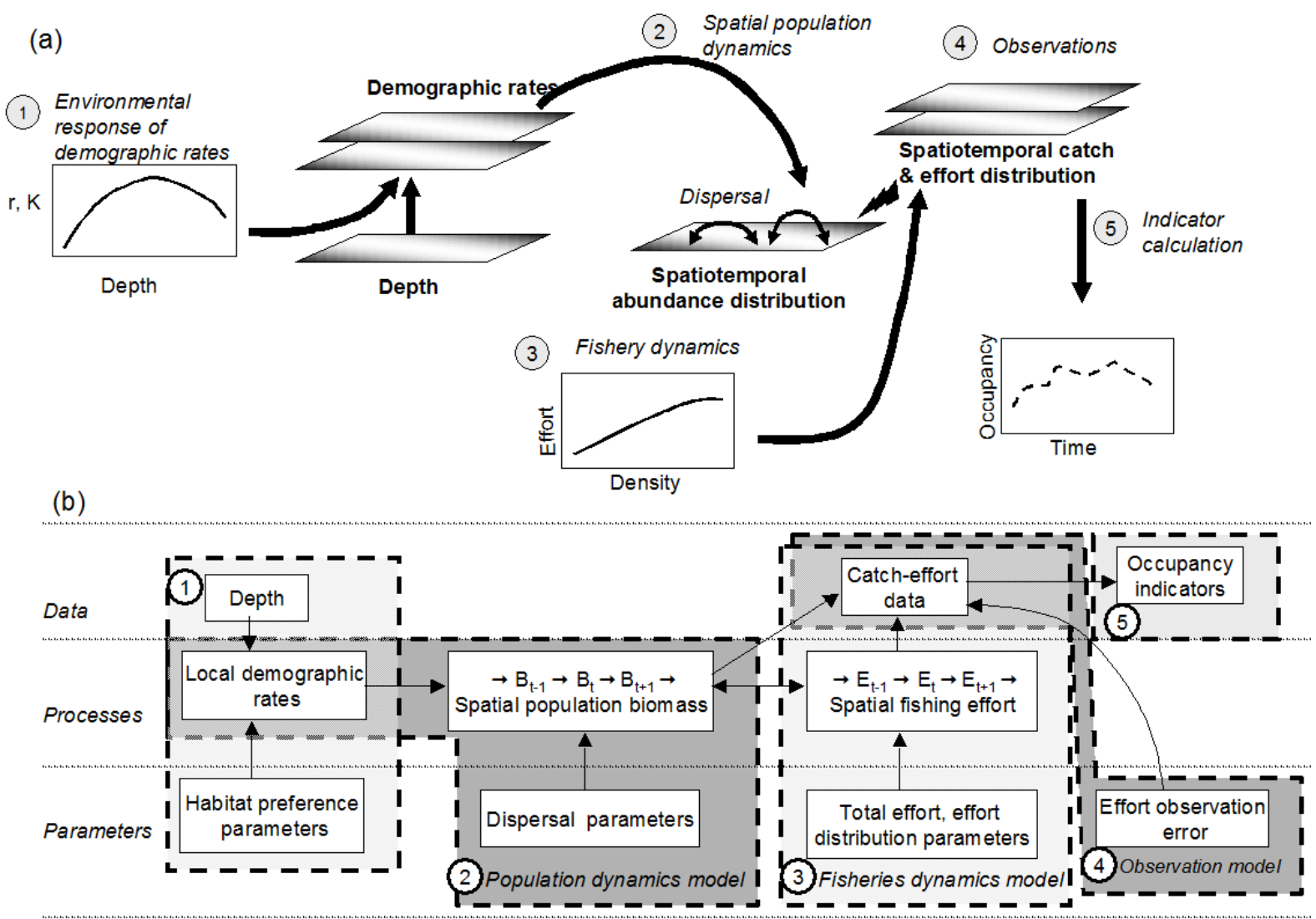

Fig. 1. Schematic view of simulation set up. (a) A hierarchy of five processes describes the link between species depth preferences, fishery dynamics, spatiotemporal catch and effort data and occupancy indicators: (1) environmental conditions represented by depth affect local demographic rates of each species; (2) variation in local demography together with dispersal and fishing determine spatiotemporal distributions of fish biomass; (3) utility of catches drives the spatial distribution of total fishing effort, which in turn impacts fish population dynamics; (4) fishing effort leads to spatiotemporally distributed catches; (5) effort observed with error and catches are used for calculating occupancy indicators. (b) Diagram of population dynamics and fishery dynamics models showing the links relating data, processes and parameters to the occupancy indicators.

\subsubsection{Population dynamics}

The population dynamics model is a spatial version of the Schaeffer (1954) production model with the addition of a dispersal term (1) in Fig. 1):

$$
\begin{aligned}
B_{s, g, t}= & B_{s, g, t-1}+r_{s, g, t-1}^{*} B_{s, g, t-1} \\
& -\frac{1}{V_{s}} \sum_{g^{\prime}} \frac{\left|B_{s, g^{\prime}, t-1}-B_{s, g, t-1}\right|\left(r_{s, g^{\prime}, t-1}^{*}-r_{s, g, t-1}^{*}\right)}{\Delta\left(g, g^{\prime}\right)}-C_{s, g, t-1}
\end{aligned}
$$

where $B_{s, g, t}$ is the biomass of species $s$ in grid cell $g$ at time step $t, r_{s, g, t-1}^{*}$ is the realised intrinsic growth rate and $C_{s, g, t}$ are catches. The realised intrinsic growth rate in a given grid cell depends on the maximum intrinsic growth rate $r_{s, g}$, which in turn depends on habitat suitability (1) in Fig. 1), the local biomass and carrying capacity. We assumed that the slope of the relationship between $B_{s, q, t}$ and $r_{s, q, t}^{*}$ was constant across grid cells, allowing it to be represented using the mean values $\bar{r}_{s}$ and $\bar{K}_{s}$ :

$$
r_{s, g, t}^{*}=r_{s, g}\left(1-\frac{B_{s, g, t}}{K_{s, g}}\right)=r_{s, g}-\bar{r}_{s} \frac{B_{s, g, t}}{\bar{K}_{s}} .
$$

This representation simply states that proportional differences in $r_{s, g}$, between grid cells are reflected in the carrying capacity, and vice versa. As biomass increases toward the carrying capacity $K_{s, g}=\bar{K}_{s} r_{s, g, t} / \bar{r}_{s}, r_{s, g, t}^{*}$ goes zero in the usual manner. Similarly, the maximum intrinsic growth rate $r_{s, q}$ is approached when local biomass is close to zero. The redistribution of biomass across grid cells (penultimate term in Eq. (1)) occurs according to the principles of spatial biogeography (MacCall 1990). This theory proposes that individuals will move in response to density-dependent spatial differences in realised growth, with an ideal free distribution being reached at equilibrium. This means that in equation (1) individuals will move to areas with less biomass and/or higher growth potential, but will do this to a lesser extent if such areas are further away. Thus, movement is a function of the gradients of biomass and realised intrinsic growth rates, the haversine distance $\Delta\left(g, g^{\prime}\right)$ between the centre point of grid cell pairs $g$ and $g^{\prime}$, and the viscosity parameter $V_{s}$. The haversine distance is the shortest distance between two points on the surface of a sphere. The viscosity parameter determines the speed of dispersal. Highly mobile species that redistribute themselves quickly (at each time step) when biomass drops in certain areas have a viscosity close to zero, while slower moving species 
have viscosity closer to one (see Fig. S1 in the Supplementary information). As viscosity approaches infinity, the dynamics in each grid cell become isolated from the remaining population and equation (1) reduces to a localised Schaeffer model.

\subsubsection{Fishery dynamics}

The dynamics of the spatial distribution of total annual fleet fishing effort $E_{t}^{T O T}$ is governed by the utility $U_{g, t-1}$ of each grid cell, and an elasticity parameter $\lambda$ (3) in Fig. 1):

$$
E_{g, t}=E_{t}^{T O T} \frac{\left(U_{g, t-1}\right)^{\lambda}}{\Sigma_{g}\left(U_{g, t-1}\right)^{\lambda}} .
$$

To mimic fishers returning to areas where CPUE was high in the past (Hutton et al. 2004), the utility of each grid cell was set equal to the catch per unit effort of a list of target species in the previous time step:

$$
U_{g, t}=\frac{\sum_{s \epsilon S} C_{s, g, t}}{E_{g, t}} .
$$

The list of target species was modified to model the effects of different fishery effort allocation behaviours (see scenario description below). The value of the elasticity parameter $\lambda$ determines how closely the spatial distribution of fishing effort follows that of the utility (CPUE) of the target species. If $\lambda=1$, the spatial distribution of fishing effort is exactly the same as for the target species CPUE; if $\lambda>1$, proportionally more effort is expended in areas with higher CPUE; if $1>\lambda>0$, proportionally less effort is expended in areas with higher CPUE; and if $\lambda=0$, the effort distribution is uniform across grid cells.

Using the spatially distributed effort, the catch per grid cell is then computed as:

$$
C_{s, g, t}=q_{g} E_{g, t} B_{s, g, t}
$$

where the catchability $q_{g}$ represents the proportion of the total area of the grid that is covered by a single unit of effort, multiplied by an efficiency term (Paloheimo and Dickie 1964). Catchability is specific to the size of each grid cell (see Parameterization below) and assumed constant over time and across species. As a result, the exploitation rate $H_{s, g, t}$ is also constant across species but variable in space:

$$
H_{s, g, t}=\frac{C_{s, g, t}}{B_{s, g, t}}=q_{g} E_{g, t} .
$$

To account for difficulties in determining fishing effort, in certain simulations observed effort $e_{g, t}$ in each grid cell was simulated assuming a normal random observation error (4) in Fig. 1):

$$
e_{g, t} \sim N\left(E_{g, t}, \sigma_{g, t}^{2}\right)
$$

with the normal distribution parameterised by a constant coefficient of variation $C V_{E}=\sigma_{g, t} / E_{g, t}$. Negative observed effort was set at zero.

Using catches from equation (5) and observed effort from equation (7), occupancy $\mathrm{O}_{75}$, corresponding to the proportion of the total area including $75 \%$ of CPUE, was estimated (5) in Fig. 1), with one value per time step.

\subsubsection{Parameterization}

The modelled grid encompassed 49 ICES rectangles (ICES rectangles are $1^{\circ}$ longitude by $0.5^{\circ}$ latitude) corresponding to the core area of the case study deep-water fishery in recent years. Grid cell depths were derived from information on mean fishing depths (Fig. 2a). Model parameter values are summarised (Tables 1 and 2) for baseline runs and those used in the sensitivity study (see below).

Four simulated species were defined by choosing appropriate values for the mean population growth rate $\bar{r}_{s}$ and the mean carrying capacity $\bar{K}_{S}$ (Table 2 ), and a depth preference function (Fig. 2b). FASTMID has a relatively fast growth rate but low carrying capacity and is distributed primarily on the continental slope at intermediate depths; it mimics black scabbardfish. MEDUPPER has intermediate growth rate and carrying capacity and is primarily distributed on the upper continental slope, similar to blue ling. SLOWDEEP has a slow growth rate but high carrying capacity and is found primarily at the lower end of the simulated depth range, mimicking roundnose grenadier. SLOWMID, mimicking deep-water sharks, has a slow growth rate and low carrying capacity and is predominantly found at mid-slope.

The maximum intrinsic growth rate $r_{s, g}$ was varied between grid cells to represent differences in habitat suitability. Habitat suitability is commonly explained by an environmental factor such as temperature. As deep-sea species have a strong depth preference (Ehrich 1983), we used depth as a proxy for habitat suitability, which would be equivalent to habitat preference in this case. We derived depth preferences based on the depth effect in a generalised additive model of haulby-haul landings data, which is described in detail for blue ling in Lorance et al. (2010) and for roundnose grenadier and black scabbardfish in Lorance et al. (2011). Using the modelled depth effect instead of the raw landings data removes effects caused by the non-random spatial distribution of fishing effort. The simulated depth preferences were scaled between 0 and 1 (Fig. 2b). Maximum intrinsic growth rates were calculated for each simulated species by multiplying the average species specific intrinsic growth rate from Table 2 by the depth preferences and then rescaling to maintain the correct average growth rate. Due to lack of information on the speed of fish movements, the viscosity parameter $V_{s}$ (Eq. (1)) was set at 1 for all species, implying slow redistribution, but the value was varied in the sensitivity study.

To make the spatial distribution of fishing effort follow that of the CPUE of the target species, the elasticity parameter $\lambda$ (Eq. (3)) was set at 1 . The value was doubled in the sensitivity study.

The proportion $q_{g}$ of the surface of grid cell $g$ fished by a single haul (Eq. (5)) was chosen in the following way. First, the swept area of a single haul was obtained by assuming a haul duration of $6 \mathrm{~h}$, a trawl width of $28 \mathrm{~m}$, and a towing speed of 2.5 knots $\left(0.78 \mathrm{~km}^{2}\right)$, which corresponds to the current average in the French fishery. Next, it was arbitrarily assumed that the catch efficiency was 0.5 (Blanchard et al. 2008). Finally the value was divided by the surface area of each grid cell, noting that grid cell areas get smaller towards the North.

The values chosen for the observation error of fishing effort $C V_{E}$ varied between the questions that the simulation 
(a)

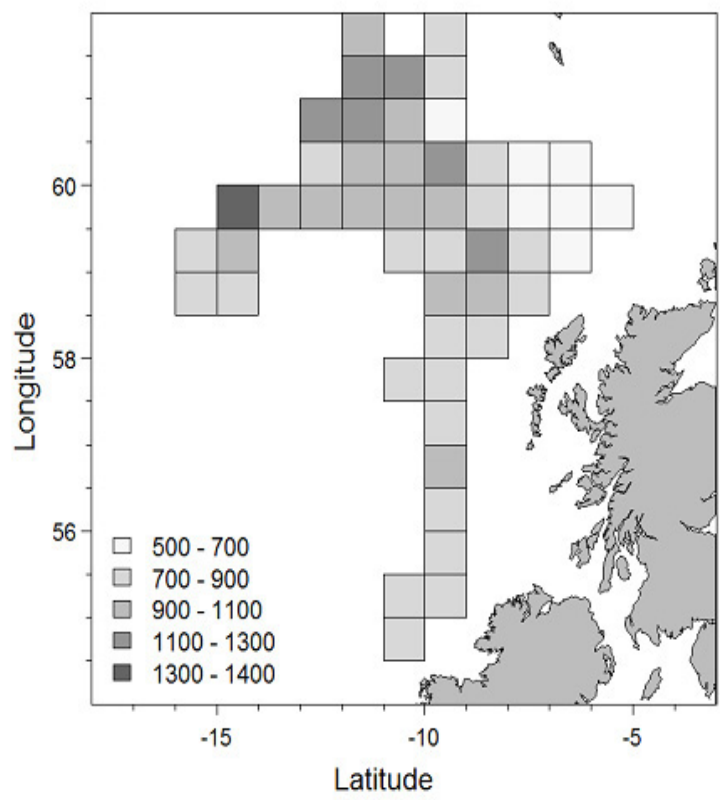

(b)

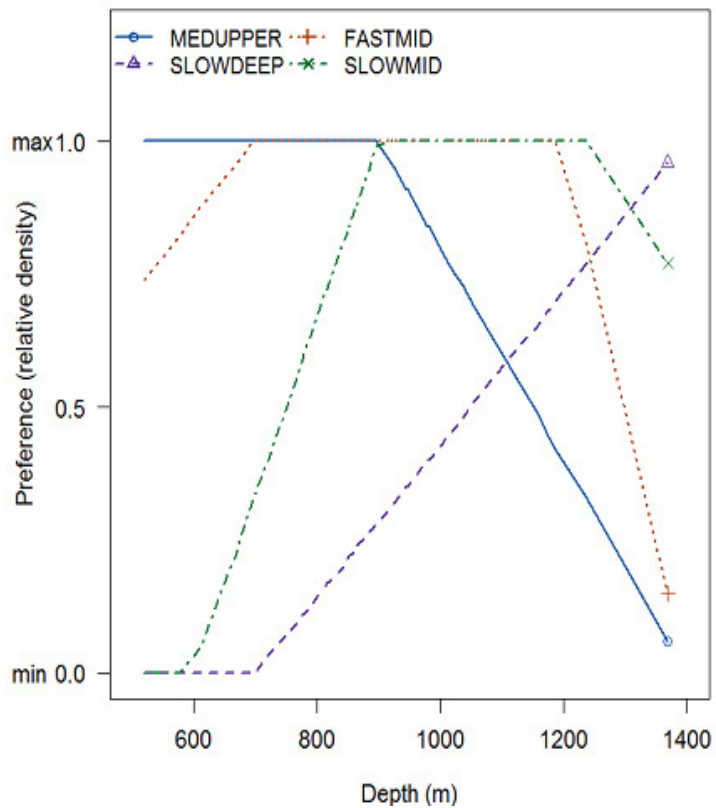

Fig. 2. (a) Map of grid cell depths used in the simulation study. (b) Depth preference curves for simulated species.

Table 1. The four simulated species that mimic deep-water fish species.

\begin{tabular}{lcccc}
\hline Simulated species & Growth rate & Carrying capacity & Habitat & Species mimicked \\
\hline FASTMID & Relatively fast & Low & Continental slope at intermediate depths & Black scabbardfish \\
\hline MEDUPPER & Intermediate & Intermediate & Upper continental slope & Blue ling \\
\hline SLOWDEEP & Slow & High & Lower end of the simulated depth range & Roundnose grenadier \\
\hline SLOWMID & Slow & Low & Mid-slope & Deep-water sharks \\
\hline
\end{tabular}

Table 2. Parameter values for the simulation study (baseline runs and sensitivity runs) of four simulated species mimicking deep-water fish species.

\begin{tabular}{|c|c|c|c|}
\hline Parameter & Definition & Equation & Values \\
\hline$V_{s}$ & Viscosity of spatial redistribution & 1 & $\begin{array}{c}\text { baseline: } 1 \text { all species } \\
\text { sensitivity: } 0.1 \text { all species }\end{array}$ \\
\hline $\bar{K}_{s}$ & $\begin{array}{l}\text { Mean carrying capacity }(t) \text { per } \\
\text { grid cell for species } s\end{array}$ & 2 & $\begin{array}{l}\text { MEDUPPER: } 1626 \\
\text { SLOWDEEP: } 2586 \\
\text { FASTMID: } 1034 \\
\text { SLOWMID: } 914\end{array}$ \\
\hline $\bar{r}_{s}$ & $\begin{array}{l}\text { Mean intrinsic growth } \\
\text { rate for species } s\end{array}$ & 2 & $\begin{array}{l}\text { MEDUPPER: } 0.24 \\
\text { SLOWDEEP: } 0.15 \\
\text { FASTMID: } 0.43 \\
\text { SLOWMID: } 0.15\end{array}$ \\
\hline$E_{t}^{T O T}$ & $\begin{array}{c}\text { Total fishing effort (number } \\
\text { of hauls) }\end{array}$ & 3 & depends on scenario, see Table 3 \\
\hline$\lambda$ & Elasticity in utility function & 3 & $\begin{array}{c}\text { baseline: } 1 \\
\text { sensitivity: } 2\end{array}$ \\
\hline$q_{g}$ & $\begin{array}{l}\text { Proportion of grid cell } g \text { fished } \\
\text { by single haul }\end{array}$ & 5,6 & $1.085 \times 10^{-4}-1.321 \times 10^{-4}$ \\
\hline$C V_{E}$ & $\begin{array}{c}\text { Coefficient of variation of normal } \\
\text { observation error for effort }\end{array}$ & 7 & $0,0.1,0.2$ \\
\hline
\end{tabular}


Table 3. Simulation study details and results. List of fishing effort scenarios, their target species and total effort and estimated slopes $\beta$ for the relationship $\log O(B)=\alpha+\beta \log (B)$, where $B$ is biomass and $O(B)$ simulated occupancy. The target species determine the spatial distribution of total fishing effort via the utility function (Eq. (3)). The total fishing effort (number of hauls per time step) is used for equilibrium runs and as the starting value for scenarios. The dynamics of the four simulated species are defined by their growth rate and carrying capacity (Table 2) and relative depth distribution (Fig. 2b).

\begin{tabular}{|c|c|c|c|c|c|c|c|}
\hline \multirow[t]{2}{*}{ Scenario } & \multirow{2}{*}{$\begin{array}{c}\text { Target species / } \\
\text { Effort distribution }\end{array}$} & \multirow[t]{2}{*}{ Effort change } & \multirow[t]{2}{*}{ Fishing effort } & \multicolumn{4}{|c|}{ Slope $\beta$} \\
\hline & & & & FASTMID & MEDUPPER & SLOWDEEP & SLOWMID \\
\hline $\mathrm{S}_{\mathrm{FM}-\mathrm{dec}}$ & FASTMID & decrease & 87693 & 0.015 & 0.071 & 0.55 & 0.616 \\
\hline $\mathrm{S}_{\mathrm{MU}-\mathrm{dec}}$ & MEDUPPER & decrease & 51299 & 0.093 & -0.017 & 0.741 & 0.3 \\
\hline $\mathrm{S}_{\mathrm{SD}-\mathrm{dec}}$ & SLOWDEEP & decrease & 49187 & 0.52 & 0.689 & -0.205 & 0.299 \\
\hline$S_{\text {all-dec }}$ & all 4 species & decrease & 54130 & 0.114 & 0.142 & 0.114 & 0.084 \\
\hline$S_{\text {uni-dec }}$ & uniform effort distribution & decrease & 54130 & 0.044 & 0.072 & 0.314 & 0.043 \\
\hline $\mathrm{S}_{\mathrm{FM}-\mathrm{inc}}$ & FASTMID & increase & 87693 & 0.008 & 0.066 & 0.931 & 3.824 \\
\hline $\mathrm{S}_{\mathrm{MU}-\mathrm{inc}}$ & MEDUPPER & increase & 51299 & 0.091 & -0.016 & 0.973 & 0.406 \\
\hline $\mathrm{S}_{\mathrm{SD}-\mathrm{inc}}$ & SLOWDEEP & increase & 49187 & 0.588 & 1.057 & -0.11 & 0.612 \\
\hline $\mathrm{S}_{\text {all-inc }}$ & all 4 species & increase & 54130 & 0.086 & 0.084 & 0.119 & 0.089 \\
\hline$S_{\text {uni-inc }}$ & uniform effort distribution & increase & 54130 & 0.048 & 0.061 & 0.361 & 0.044 \\
\hline
\end{tabular}

addressed; for stochastic runs, only one realisation of observed effort time series was simulated.

Two sensitivity runs were carried out for the viscosity $V_{S}$ and elasticity $\lambda$ parameter values (Table 2). A value of $V_{s}=0.1$ corresponds to fast spatial redistribution between time steps. When elasticity is $\lambda=2$, proportionally more fishing effort is allocated to grid cells with higher CPUE of the target species in the previous time step.

\subsubsection{Fishing effort scenarios}

Ten fishing effort scenarios were defined (Table 3). Each scenario consists of a target species, which determines the spatial distribution of effort via the utility function (Eqs. (3) and (4)), and the type of change in fishing effort (doubling or halving) over time. Five target species were considered: FAST$\operatorname{MID}\left(\mathrm{S}_{\mathrm{FM}}\right)$, MEDUPPER $\left(\mathrm{S}_{\mathrm{MU}}\right)$, SLOWDEEP $\left(\mathrm{S}_{\mathrm{SD}}\right)$, all four simulated species $\left(\mathrm{S}_{\mathrm{all}}\right)$, and no target species, i.e., uniform effort distribution ( $\lambda=0$ in Eq. (3), $\left.S_{\text {uni }}\right)$.

As a first step for all scenarios, the model was run to equilibrium (100 time steps) keeping total fishing effort constant at a value corresponding roughly to exploitation at maximum sustainable yield (MSY) for the single species targets (fourth column in Table 3$)$. For scenarios targeting all species $\left(S_{\mathrm{all}}\right)$ or none $\left(S_{\text {uni }}\right)$, the total effort used was a compromise between the individual species efforts. The biomass for all four species in each grid cell was initiated by setting it at half the carrying capacity (Table 2), which corresponds to the biomass at MSY in a surplus production model. Second, total effort was increased (decreased) over the next 20 time steps depending on the scenario. For all time series, occupancy $O$ (CPUE) was estimated as the proportion of the total area covered by $75 \%$ CPUE; the $75 \%$ level was shown to be a reliable value in the case study.

\subsubsection{Analysis}

To address the four main questions of the study, loglinear models were used to describe the relationships between biomass B and occupancy O (Frisk et al. 2011) for the ten fishing effort scenarios (Table 3 )

$$
\log (O)=\alpha+\beta \log (B)
$$

where $\alpha$ and $\beta$ are the intercept and slope, respectively. Twosided t-tests were used to evaluate whether $\beta$ was significantly different from zero at an $\alpha$-level of 0.05 .

For question (1), "Is occupancy a sensitive indicator of population abundance?", the slope $\hat{\beta}_{B}$ of the log-linear relationship between population biomass $B$ and population occupancy $O(B)$ was estimated for each scenario and simulated species. Population occupancy $O(B)$ was derived from the simulated biomass values for each grid cell $B_{s, g, t}$. For $\hat{\beta}_{B}$ slopes close to 1 , occupancy is a sensitive indicator of biomass, while it is not for values close to 0 .

For question (2), "Does fishers following fish alter the positive macroecological relationship between occupancy and abundance?", the sign of the slopes $\hat{\beta}_{B}$ estimated above was investigated for fishing effort scenarios with a single or multiple target species $\left(\mathrm{S}_{\mathrm{FM}}, \mathrm{S}_{\mathrm{MU}}, \mathrm{S}_{\mathrm{SD}}, \mathrm{S}_{\mathrm{all}}\right)$ for each of the four simulated species. In particular, it was checked whether the relationship was positive $\left(\hat{\beta}_{B}>0\right)$, as it should be if fishing did not alter the form of the relationship. The scenario $S_{\text {uni }}$ with uniform fishing effort distribution provided the unaltered reference situation.

For question (3), "Does the activity of pursuing fish negatively affect occupancy indicator estimates derived from catch and effort data?", log-linear regressions were fitted to population biomass $B$ and occupancy estimates obtained from CPUE values with no observation error $\mathrm{O}\left(\mathrm{CPUE}_{0}\right)$ providing slope estimates $\hat{\beta}_{0}$. For each fishing effort scenario and simulated species, the sign of the slope $\hat{\beta}_{0}$ was compared to the sign of $\hat{\beta}_{B}$ obtained above. Again the scenario $S_{\text {uni }}$ with uniform fishing effort distribution provided the reference situation.

For question (4), "How does uncertainty in fishing effort data affect occupancy indicator estimates?", log-linear regressions were fitted for population biomass and occupancy estimates derived from CPUE values, with three levels of observation error $\left(\mathrm{CV}_{\mathrm{E}}=0: O\left(\mathrm{CPUE}_{0}\right), \mathrm{CV}_{\mathrm{E}}=0.1: O\left(\mathrm{CPUE}_{0.1}\right)\right.$, 

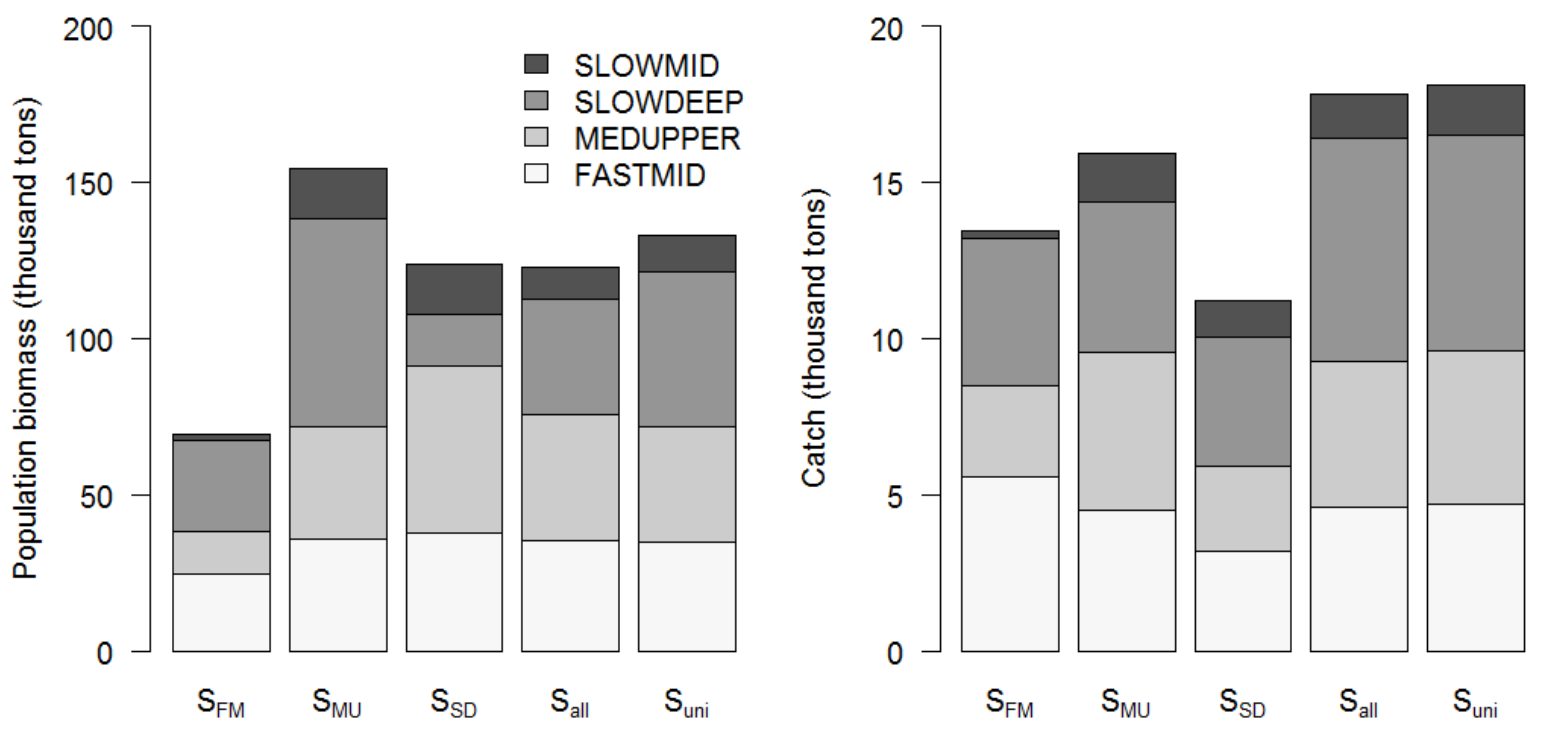

Fishing effort scenario

Fig. 3. Simulated equilibrium total biomass and catches for four simulated species under five fishing effort scenarios (see Table 3). Total effort was selected to correspond roughly to maximum sustainable yield (MSY) exploitation of the target simulated species of the fishing effort scenario.

$\left.\mathrm{CV}_{\mathrm{E}}=0.2: O\left(\mathrm{CPUE}_{0.2}\right)\right)$. The values and signs of the corresponding slope estimates $\hat{\beta}_{0}, \hat{\beta}_{0.1}$, and $\hat{\beta}_{0.2}$ were then compared.

\subsection{Case study}

French logbook effort and landings data for blue ling, black scabbardfish, roundnose grenadier and deep-water sharks for the years 1993 to 2010 were extracted from the database maintained by Ifremer for the area to the northwest of the British Isles (ICES Divisions Vb and VIa). Fishing effort corresponded to hours spent fishing multiplied by vessel power $(\mathrm{kW})$. Landings and effort data were summed on an annual basis by ICES rectangle. Only fishing days where deep-water species represented more than $60 \%$ of the total landings were selected so as to avoid marginal areas that are visited by the same vessels to target other species. This led to a dataset containing 26 rectangles with data for all years. Because discard estimates were not available for all years, only landings data were used. In any case, discards should not affect the occupancy indicators unless they had a spatial structure, for which there is no evidence.

Owing to a lack of survey data, an index of population abundance in the study area was derived for each species using haul-by-haul landings data from part of the French fishery and the methods described in Lorance et al. (2011) for the period 2000 to 2009. Briefly, standardised abundance indices were obtained by fitting generalised additive models to the landings data (in weight) accounting for vessel, month, depth, and rectangle effects. The abundance indices are then predictions for a standard vessel in January.

Finally, for each species and year occupancy $\mathrm{O}_{75}$ was calculated.

\section{Results}

\subsection{Simulation study}

\subsubsection{Equilibrium results}

The equilibrium population biomasses for each species were similar for all fishing effort scenarios, except scenario $\mathrm{S}_{\mathrm{FM}}$, in which they were lower (Fig. 3, left). Lowest total equilibrium catches were obtained for scenario $\mathrm{S}_{\mathrm{SD}}$, and highest for scenarios $S_{\text {all }}$ and $S_{\text {uni }}$ (Fig. 3, right). Thus, the target species of the fishing effort scenario had a strong influence on the equilibrium biomass, total catch and catch composition. Largest overall equilibrium catches were obtained when fishing effort was more widely distributed $\left(S_{\text {all }}\right.$ and $\left.S_{\text {uni }}\right)$, while the highest population biomass summed over all species resulted from targeting blue ling $\left(\mathrm{S}_{\mathrm{MU}}\right)$.

\subsubsection{Is occupancy a sensitive indicator of population biomass?}

For the scenarios with uniformly distributed fishing effort, the slope estimates $\hat{\beta}_{B}$ of the log-linear relationships between population biomass $B$ and population occupancy $O(B)$ ranged from 0.043 to 0.361 (Table 3$)$; increasing $\left(S_{\text {uni-inc }}\right)$ and decreasing $\left(\mathrm{S}_{\text {uni-dec }}\right)$ total effort scenarios resulted in very similar slope estimates for each species. Introducing targeting of one or all species increased the slopes for all species except for the target species of the scenario and for SLOWDEEP in the scenarios targeting all species $\left(S_{\text {all-inc }}\right.$ and $\left.S_{\text {all-dec }}\right)$ (Table 3$)$; the interquartile range of slope estimates $\hat{\beta}_{B}$ spanned from 0.058 to 0.528 . Slope values close to zero indicate low sensitivity of occupancy as an indicator of biomass change. 
(a)

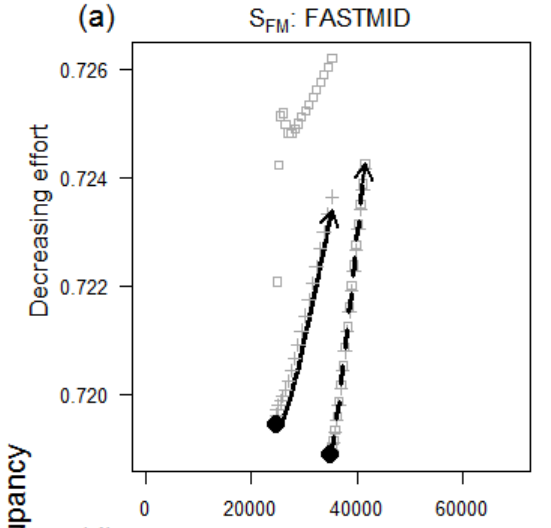

(d)

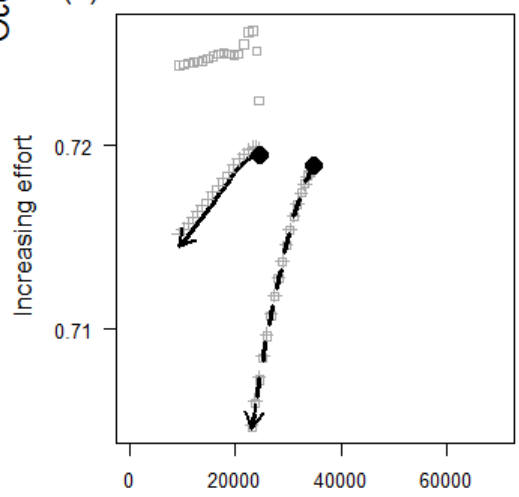

(b) $\quad \mathrm{S}_{\text {MU: }}$ MEDUPPER

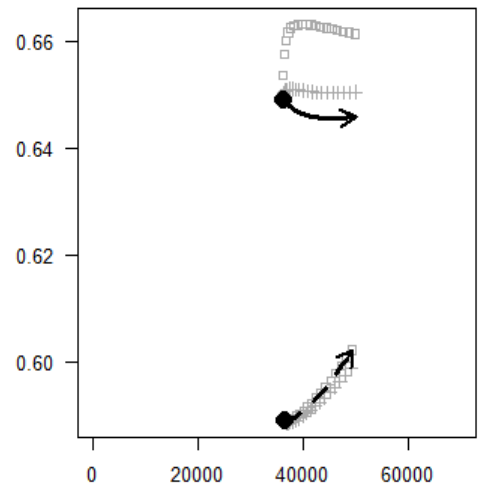

(e)

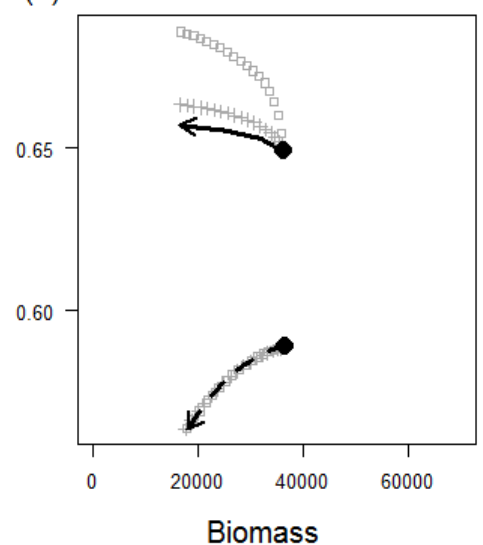

(c)

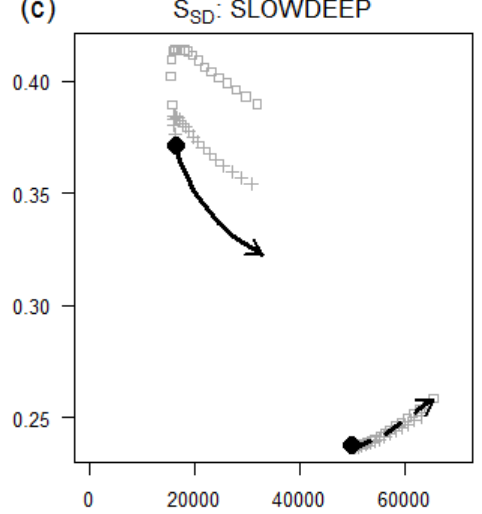

(f)

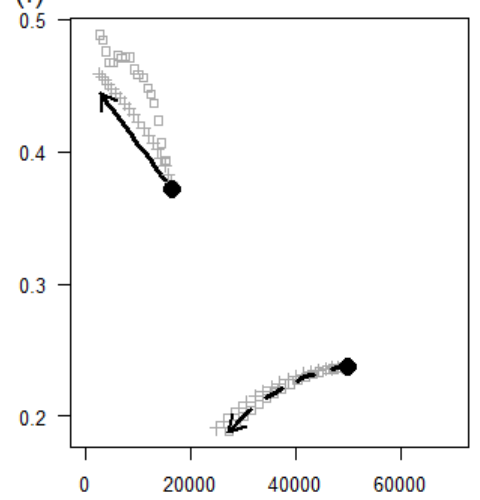

Fig. 4. Simulated true abundance-occupancy relationships for simulated species FASTMID, MEDUPPER and SLOWDEEP when they are the target species of the fishery (see Table 3 for fishing effort scenarios, continuous line) and when effort distribution is uniform (dashed line). All simulations are run to equilibrium, with fishing effort corresponding roughly to MSY followed by two fishing effort scenarios: halving of total fishing effort or doubling over 20 time steps. Dots indicate the first simulation time step and arrows the last. Sensitivity runs are shown in grey: squares $\lambda=2$; plus signs $V_{s}=0.1$ (see Table 2 for parameter definitions).

\subsubsection{Does fishers following fish alter the positive macroecological relationship between occupancy and abundance?}

The estimated slopes $\hat{\beta}_{B}$ of the log-linear relationships between population biomass $B$ et population occupancy $O(B)$ were positive for all fishing effort scenarios and all simulated species except for species MEDUPPER for scenario $S_{M U}$ and SLOWDEEP for scenario $S_{S D}$, for which they were negative (Table 3). This confirms that the positive macroecological relationship between occupancy and abundance can be altered, but only for some single species targets.

To show the alterations, Figure 4 presents the relationships for simulated species FASTMID, MEDUPPER and SLOWDEEP for the scenarios in which each species was the target species, i.e., scenarios $\mathrm{S}_{\mathrm{FM}}, \mathrm{S}_{\mathrm{MU}}$ and $\mathrm{S}_{\mathrm{SD}}$ respectively. For each species, the positive relationship resulting from a uniform effort distribution, scenario $S_{\text {uni }}$, is shown as a reference. The alterations to the shapes of the relationships caused by different fishing effort scenarios can be summarised as follows. First, occupancy levels for MEDUPPER and SLOWDEEP in scenarios $\mathrm{S}_{\mathrm{MU}}$ and $\mathrm{S}_{\mathrm{SD}}$, respectively, were always (at all time steps) higher than in scenario $S_{\text {uni }}$, both for increasing (Fig. 4b,c) and decreasing effort (Fig. 4e,f). Second, total species biomass for FASTMID (Fig. 4a,d) and SLOWDEEP (Fig. 4c,f) was higher for scenario $S_{\text {uni }}$ at all time steps compared with scenarios $S_{\mathrm{FM}}$ and $\mathrm{S}_{\mathrm{SD}}$ respectively. Third, scenarios $S_{M U}$ and $S_{S D}$ led to negative relationships between logbiomass and log-occupancy for MEDUPPER (Fig. 4b,e) and SLOWDEEP (Fig. 4c,f), respectively. In contrast, for scenario $\mathrm{S}_{\text {uni }}$, all relationships were positive for all species, as expected. A negative relationship between total biomass and occupancy means that a species becomes less vulnerable to fishing as it becomes more spread when population biomass decreases.

The results of the two sensitivity runs are also shown (Fig. 4). Dividing the viscosity parameter $V_{s}$ by ten, which increases redistribution speed, did not have any impact. In contrast, doubling the elasticity parameter $\lambda$ by two, which meant fishing effort was more concentrated in high CPUE areas, led to transient effects and differently shaped occupancyabundance relationships during the early time steps.

\subsubsection{Does pursuing fish adversely affect occupancy indicator estimates derived from catch and effort data?}

The estimated slopes $\hat{\beta}_{0}$ of the log-linear relationship between population biomass and CPUE-derived occupancy 

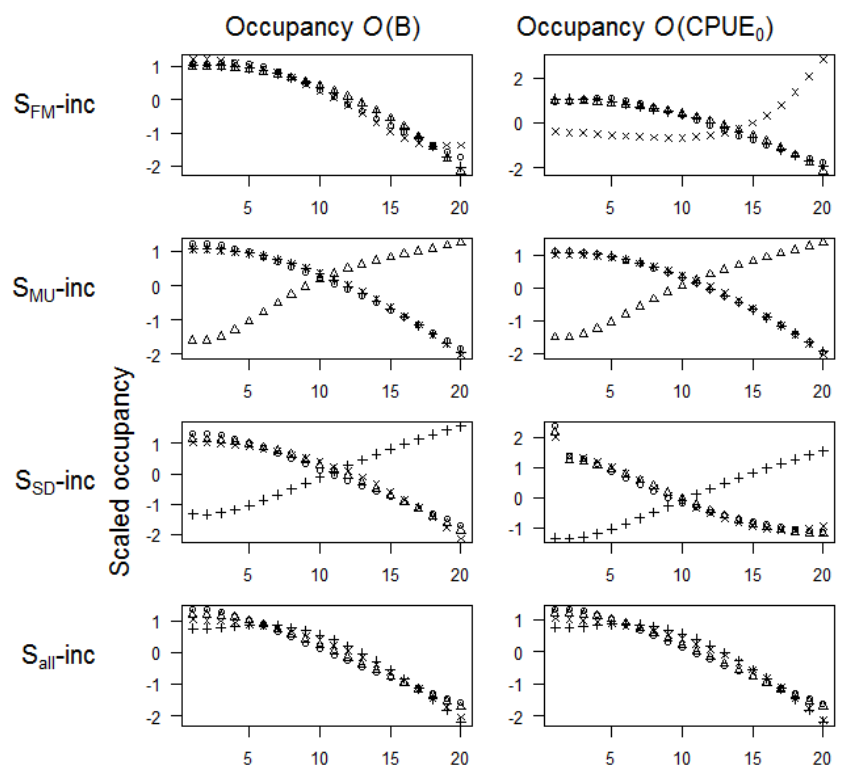

$\mathrm{S}_{\text {uni }}$-inc
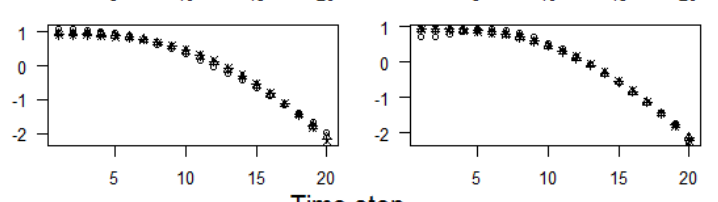

Fig. 5. Time series of scaled population occupancy $\mathrm{O}(\mathrm{B})$ and CPUEderived occupancy $O\left(\mathrm{CPUE}_{0}\right)\left(\mathrm{CV}_{E}=0\right)$ for four simulated species and five fishing effort scenarios with total fishing effort doubling from time step 1 to 20 (see Table 3). Simulated species: FASTMID $(\bigcirc)$, MEDUPPER $(\triangle)$, SLOWDEEP (+), SLOWMID (X).

$\mathrm{O}\left(\mathrm{CPUE}_{0}\right)$ were positive for all fishing effort scenarios and all species except for the target species of single target scenarios, i.e., FASTMID for scenario $\mathrm{S}_{\mathrm{FM}-\mathrm{dec}}$ (decreasing effort) and SLOWMID for scenario $\mathrm{S}_{\mathrm{FM} \text {-inc }}$ (increasing effort), MEDUPPER for scenario $S_{M U}$ and SLOWDEEP for scenario $\mathrm{S}_{\mathrm{SD}}$, for which they were negative (not shown). Thus for simulated species FASTMID and SLOWMID, the occupancy estimates derived from catch and effort information led to an alteration in the abundance-occupancy relationship, even in the absence of any observation error for effort. This means that the time trends of CPUE-derived occupancy estimates could be misleading as a proxy for abundance time trends in certain circumstances. For example, in scenario $\mathrm{S}_{\mathrm{FM}-\mathrm{inc}}$, occupancy estimates for SLOWMID were increasing while in the underlying simulated population they were decreasing (Fig. 5).

\subsubsection{Does uncertainty in fishing effort affect occupancy indicator estimates?}

To answer this question, the estimated slopes $\hat{\beta}_{0.1}$ and $\hat{\beta}_{0.2}$ of the relationships between log-transformed biomass and occupancy estimates for two levels of effort observation error $\left(\mathrm{CV}_{\mathrm{E}}=0.1\right.$ and $\left.\mathrm{CV}_{\mathrm{E}}=0.2\right)$ were compared with the results obtained for no observation error $\hat{\beta}_{0}$. Introducing observation error in effort led to some relationships not having a slope significantly different from 0 ( $p$-value $>0.05)$, in particular for scenarios with MEDUPPER as the target species (Fig. 6), but also in one case for the scenario with uniform effort distribution $\mathrm{S}_{\text {uni-dec }}$. The number of non-significant slopes was four for $\mathrm{CV}_{\mathrm{E}}=0.1$ and five for $\mathrm{CV}_{\mathrm{E}}=0.2$. Thus, if fishing effort is only known with some error, an apparent stability in estimated occupancy might mask underlying changes in population occupancy and thus population biomass.

\subsection{Case study}

The distribution of French fishing effort during the period 1989-2010 was spatially heterogeneous and changed somewhat over the study period, with an overall decrease in level (Supplementary information Fig. S2).

A positive relationship between log-transformed occupancy $\mathrm{O}_{75}$ and the log-transformed abundance index was only found for roundnose grenadier, though the relationship was only just significant at an $\alpha$-level of 0.1 (Fig. 7). For black scabbardfish, blue ling and deep-water sharks, though the slopes were not significantly different from zero, the pattern resembled that obtained in the simulation study for scenario $\mathrm{S}_{\mathrm{MU}-\mathrm{dec}}$, for which SLOWDEEP had the largest positive slope and MEDUPPER the smallest (negative) one (Table 3).

In terms of time trends, $\mathrm{O}_{75}$ was stable for black scabbardfish, changed abruptly in the early 2000s for blue ling and decreased steadily from the mid-2000s for roundnose grenadier (Fig. 8). For deep-water sharks, estimated occupancy increased sharply at the beginning of the time series and decreased at the end. Blue ling generally had the smallest occupancy value of all species, indicating the highest aggregative spatial distribution, most likely because the landings reflected the fishery targeting blue ling spawning aggregations (see discussion).

\section{Discussion}

Spatially explicit simulations were carried out to determine whether occupancy indicators derived from commercial catch and effort data might provide reliable indications of population status for deep-water species exploited to the west of the British Isles.

First, an investigation was made of the extent to which occupancy might change when population biomass changes using the slope of the log-log relationship that corresponds to the exponent of the non-linear relationship. Non-linear relationships between CPUE and abundance have been characterised by "hyperdepletion", where the CPUE drops faster with depletion than abundance, and "hyperstability", where CPUE drops more slowly than abundance (Hilborn and Walters 1992; Wilberg et al. 2010). Hyperstability has been associated with stock, gear type and fleet behaviour (Harley et al. 2001). MacCall (1990) argues from the ideal free distribution theory of Fretwell and Lucas (1969) that the response of the fish stock to depletion is to shrink in size towards a core suitable area. Following the ideal free distribution theory in the simulation study, it was assumed that each species had spatially distinct population growth rates leading to spatial differences in population density. In the simulation study, for all species and all fishing effort scenarios (including for $\mathrm{S}_{\text {uni }}$ with fishing 

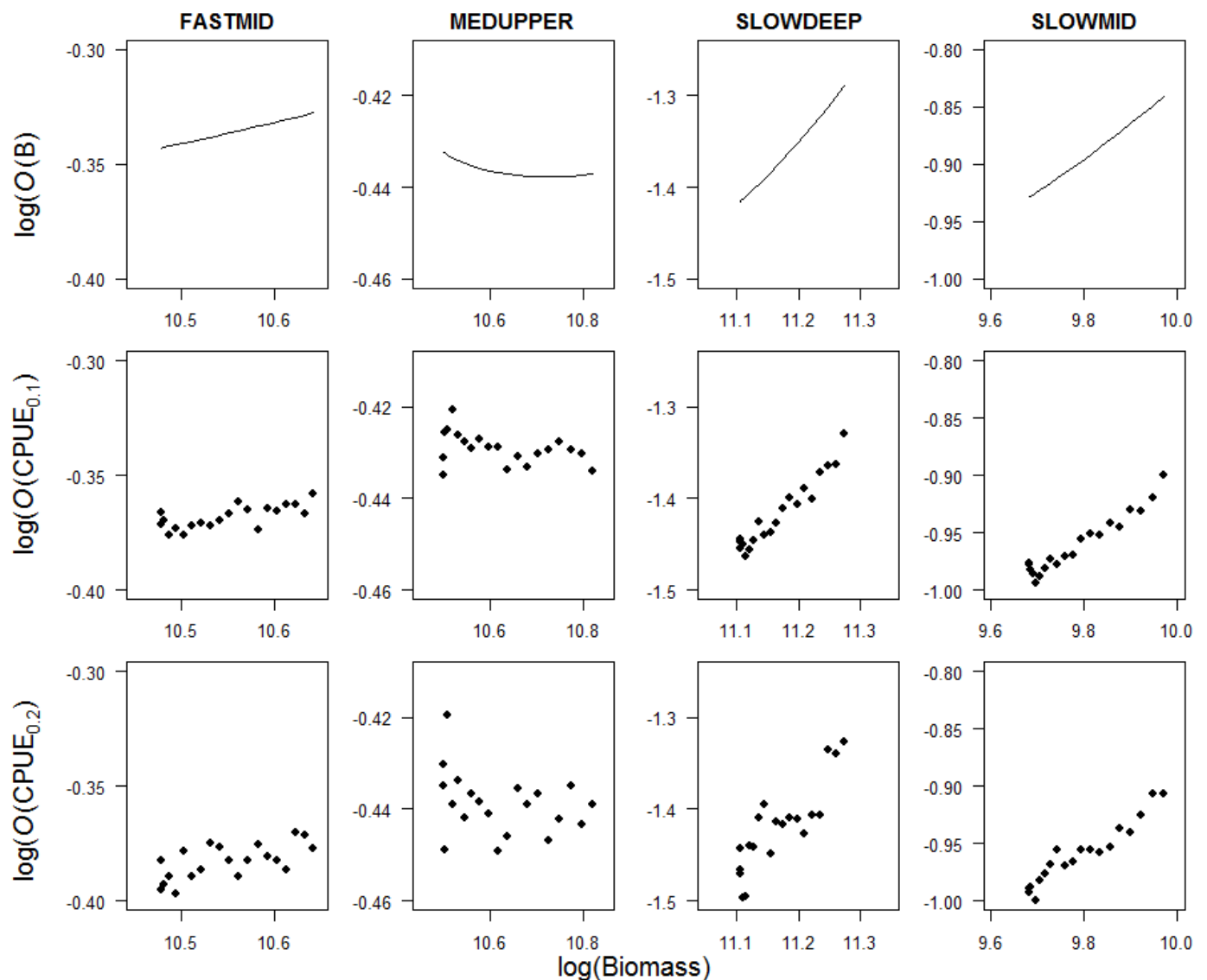

Fig. 6. Scaled population occupancy $\mathrm{O}(B)$ and CPUE-derived occupancy for four simulated species for low $\left(\mathrm{O}\left(\mathrm{CPUE}_{0.1}\right) ; \mathrm{CV}_{E}=0.1\right)$ and high effort observation error: $\mathrm{O}\left(\mathrm{CPUE}_{0.2}\right), C V_{E}=0.2$; as a function of total biomass for fishing effort scenario $\mathrm{S}_{\mathrm{MU} \text {-dec }}$ (scenarios are described in Table 3).
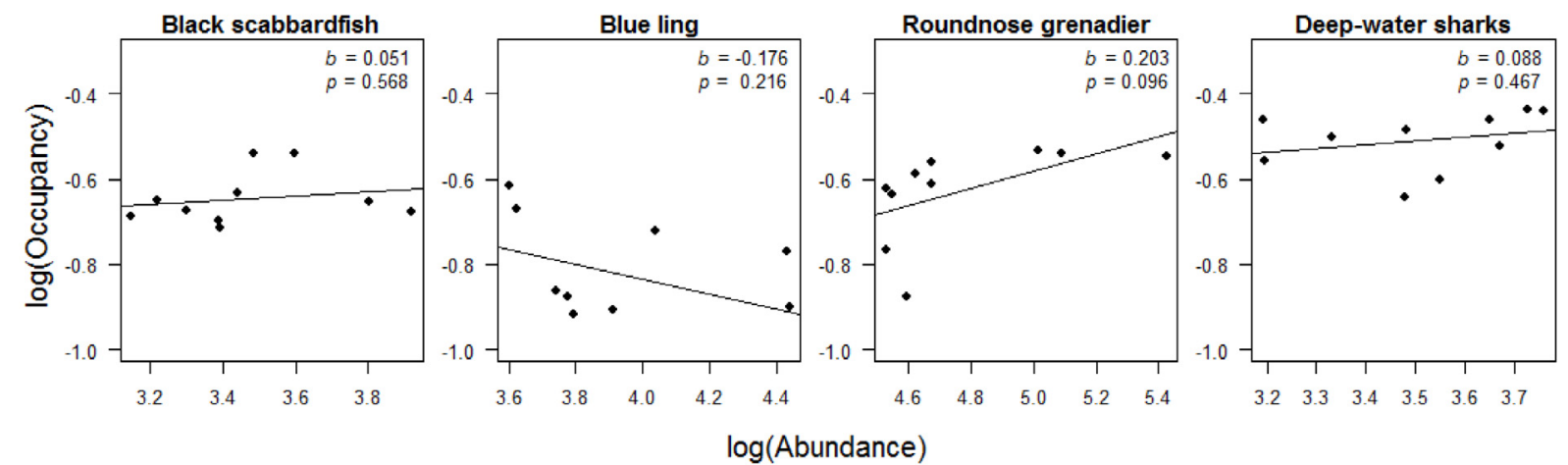

Fig. 7. Relationship between estimated log-transformed occupancy $\mathrm{O}_{75}$ and log-transformed population abundance index for the deep-water case study for the period 2000-2009. The lines are linear regression fits.

effort uniformly distributed) changes in occupancy were relatively small, even when biomass doubled or was divided by two in scenarios $S_{\text {uni-dec }}$ and $S_{\text {uni-inc }}$, respectively (Fig. 4). The slopes of the log-linear biomass-occupancy relationship ranged from -0.205 to 3.823 (interquartile range: 0.058 $0.528)$. This range of values is slightly larger than the range of slope values (0.023-0.177) found by Frisk et al. (2011), who fitted log-linear models to occupancy and abundance estimates derived from survey data for 32 demersal fish and crustacean species on Georges Bank. Hence, the results suggest that occupancy might not be a sensitive proxy for population biomass. In addition, they could also indicate a certain degree of hyperstability. These conclusions apply even without accounting for the possibility that fishers following fish could reverse the abundance-occupancy relationship.

Second, it was investigated whether fishers following fish could alter the positive macroecological relationship between occupancy and abundance. The simulation results showed that this was indeed possible: for the simulated species MEDUPPER, mimicking blue ling, and SLOWDEEP, mimicking 


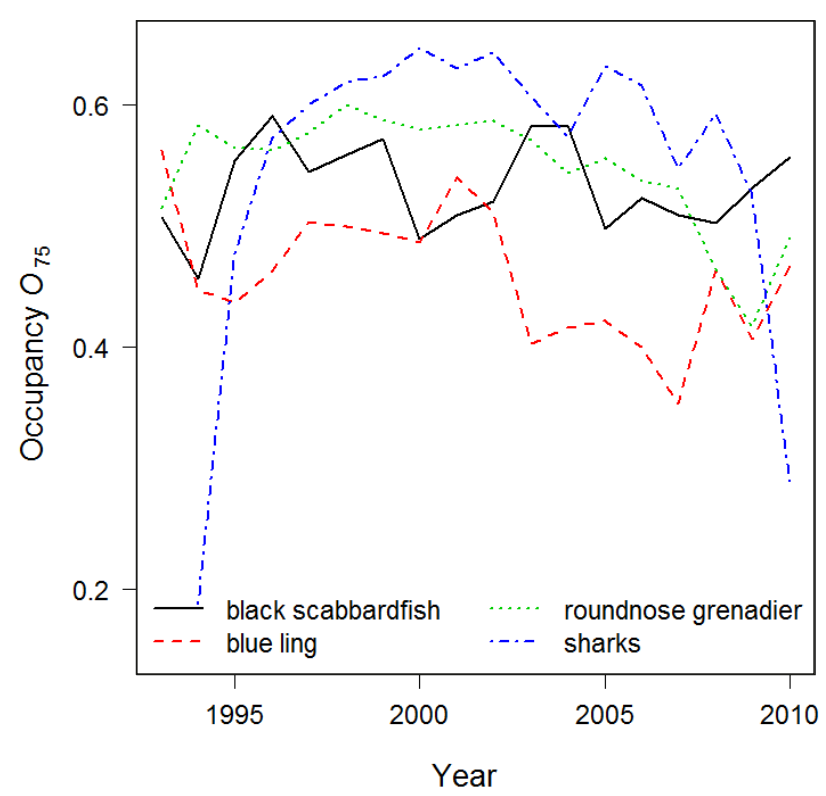

Fig. 8. Time series for estimated occupancy $\mathrm{O}_{75}$ for the deep-water case study.

roundnose grenadier, negative relationships were found for the scenarios where fishers followed the distribution of the two species exactly. These results where robust to the assumption that fish redistributed faster across grid cells (implemented by reducing the viscosity parameter for all species). In contrast, allocating more effort to areas with higher CPUE (implemented by doubling the elasticity parameter) led to transient effects with differently shaped distributions at the start of the simulation period.

Third, the question was examined of whether pursuing fish could adversely affect occupancy estimates derived from catch and effort data. The simulation results showed that this was possible, but again only for certain simulated species and certain fishing effort scenarios.

Fourth, the simulations were used to study the impact of observation error in effort data. The main effect was that estimated occupancy and biomass could become uncoupled, implying that occupancy was no longer a proxy indicator for biomass. The existence of observation error could explain the three non-significant slopes in the case study. In the simulation study, it was assumed that effort was known with error but that the effect would be the same if catches or both catches and effort were uncertain.

The simulation results are, of course, contingent on the modelling assumptions made. Model parameter values were chosen to reflect the real situation as much as possible in terms of species specific spatial population dynamics, the location of the study area and the spatial resolution. However, a number of assumptions were more arbitrary. The sensitivity of the results was evaluated by varying the value of the elasticity and the viscosity parameters. Further, the utility function (Eq. (4)), which determines the spatial distribution of fishing effort, was a simple function of the catch per unit effort for the target species in the previous time step. Among other options that have been suggested (Hilborn 2007), profit defined as sales revenue minus variable costs would also be suitable. The two quantities to be considered would be species dependent sales prices and location dependent costs. The four considered deep-water species have comparable sales prices, while variable costs can be assumed to increase with increasing distance from the harbour, which in the case of the French deep-water fishery is located on the Scottish west coast, so at similar distances. Thus, including profits in the utility function should not change the simulation results much. The way habitat preference was modelled using depth as a proxy was somewhat ad hoc. Also, habitat preference was assumed constant over time (within and between years) even though it is well known that, for example, blue ling has several distinct spawning areas (Large et al. 2010) and mature individuals will therefore carry out spawning migrations in spring. What is not known is whether those individuals return to the same location after spawning. No spawning aggregations occur for black scabbardfish because their spawning area is outside the study area around Madeira (Neves et al. 2009). Individuals are thought to emigrate south after spending a few years in the study area, but whether this migration occurs continuously or over a short season is unknown. Roundnose grenadier is considered to have poor swimming capabilities, and individuals in spawning condition are found throughout the study area during most of the year (Lorance et al. 2008). Deep-water sharks are good swimmers and highly mobile (Lorance and Trenkel 2006); segregations in sexual stages reflect some migrations related to reproduction (T. Moura pers. comm.). Thus, assuming constant habitat preferences throughout the year is reasonable for three of the considered species, but not blue ling.

In the case study, a positive relationship between logabundance and log-occupancy was only found for roundnose grenadier. The non-significant slopes for the other species could be the result of uncertainty in effort or catch data: an interpretation supported by the simulation study. An alternative explanation for the noisier relationships lies in the abundance index, whose uncertainty was ignored in the log-linear regressions. The order of magnitude of slopes and the rank of species slopes agreed well with the simulation study, in particular with scenario $S_{M U}$ with MEDUPPER (mimicking blue ling) as target species, and decreasing effort. Until the practice was prohibited in 2010, blue ling aggregations were targeted during the spawning season in spring. Since 2003, the combination of TAC reduction and effort regulation have led to a decrease in fishing effort. This decrease in effort could explain the agreement between the relative slopes of the four species and the results of scenario $\mathrm{S}_{\mathrm{MU} \text {-dec }}$. Assuming that this scenario describes the situation in recent years, the observed decrease in occupancy of roundnose grenadier would indicate a decrease in stock biomass. Given the expected weak relationship between abundance and occupancy changes for black scabbardfish, roundnose grenadier and deep-water sharks as indicated by the simulation study, and the uncertain estimates, it seems hazardous to interpret their temporal changes in the case study. However, for sharks, the strong increase in occupancy in the early 1990s and the strong decrease in 2010 can be explained. In the early 1990s, the landings of the two deepwater species studied here were mixed with other species. So the increase in occupancy is actually an increase in data quality. To protect deep-water sharks from overexploitation in 2010 , the quota for targeted fishing of deep-water sharks 
was set at 0 with an allowance for a bycatch of $10 \%$ of 2009 landings ( $3 \%$ in 2011 , subsequently none). Thus, the apparent decrease is a result of shark catches no longer being fully recorded.

For the case study, effort and landings logbook data with the resolution of an ICES statistical rectangle were used. Higher spatial resolution and possibly precision in effort data might be made possible by using vessel monitoring data (VMS). In this case, landings or catches in each rectangle would need to be apportioned to the effort data, inevitably making assumptions about the spatial distribution of each species. Further studies are needed to evaluate whether such higher resolution data would modify our findings.

In conclusion, with respect to using fisheries derived occupancy indicators for management, this study indicates that care should be taken as both weak relationships and species targeting might adversely impact the performance of occupancy indicators. Nevertheless, occupancy indicators are required for management in the context of the European Marine Strategy Framework Directive (MSFD) where distribution range and pattern of selected species impacted by human activities are needed to assess the environmental status of MSFD descriptor 1 "biodiversity". In fish communities, such species include those that have already become rare or vulnerable to fishing, primarily large, long-lived, low abundance species that are seldom or never caught by scientific surveys. The main data for these species may be fishery-dependent, either through catch statistics, on-board observations or fishers reporting under participatory monitoring. In all cases, our study provides insight into the caution needed when interpreting spatial indicators, and suggests that understanding species-specific relationships between actual (unknown) and observed abundance and occupancy is necessary to assess and interpret distributional ranges and patterns.

Acknowledgements. The study was carried out with financial support from the Commission of the European Communities under the DEEPFISHMAN project (grant agreement no. 227390). Landings and effort data were extracted from the Ifremer SIH database. We thank three anonymous referees for their constructive comments.

\section{Supplementary information} stocks.

Trenkel et al. Testing catch-per-unit-effort-derived spatial occupancy as an indicator for stock abundance: application to deep-sea

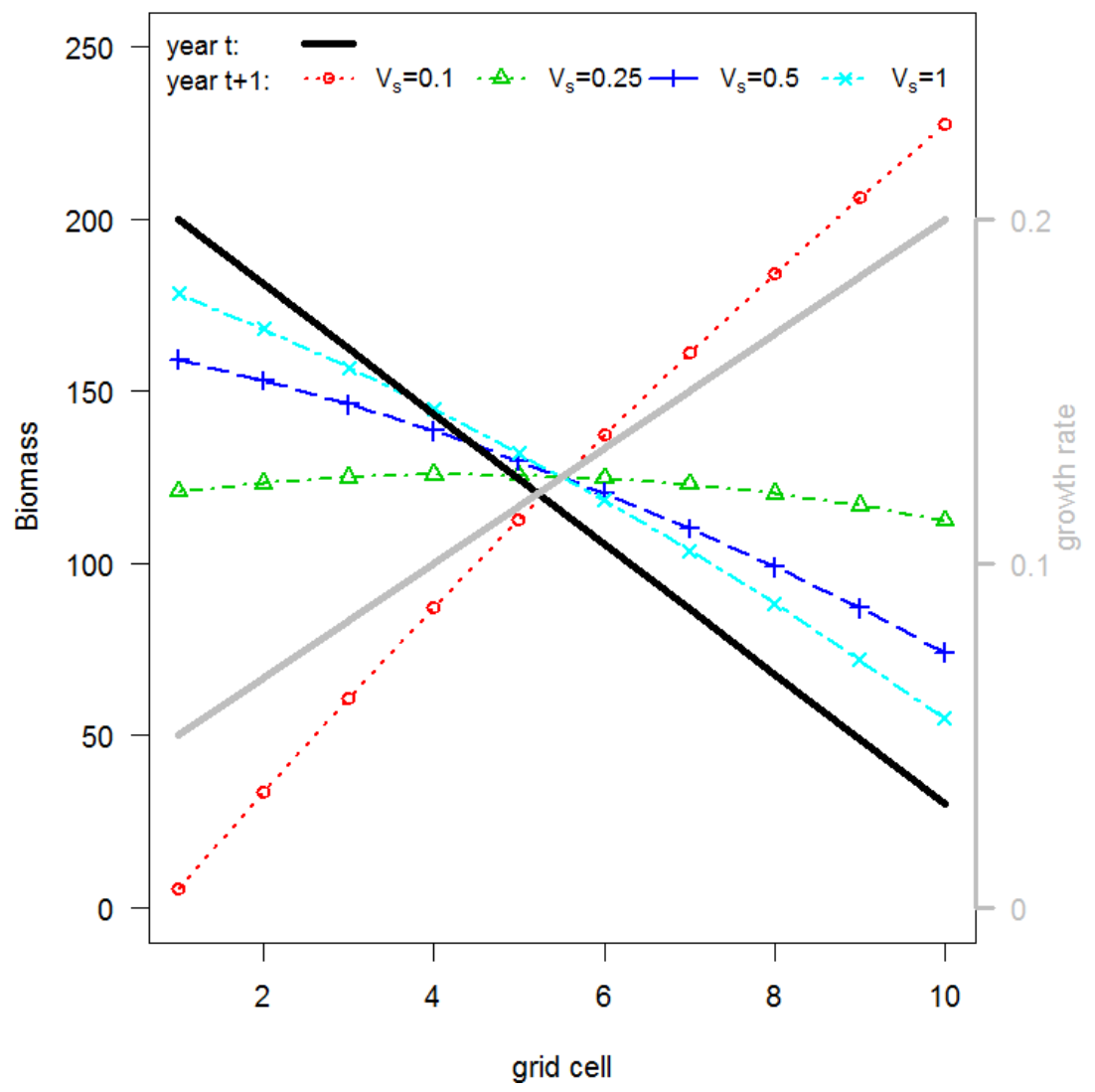

Fig. S1. Hypothetical example to illustrate the effect of the viscosity parameter $V_{s}$ in equation (1) $\left(B_{s, g, t}=B_{s, g, t-1}+r_{s, g, t-1}^{*} B_{s, g, t-1}-\right.$ $\left.\frac{1}{V_{s}} \sum_{g^{\prime}} \frac{\left|B_{s, g^{\prime}, t-1}-B_{s, g, t-1}\right|\left(r_{s, g^{\prime}, t-1}^{*}-r_{s, g, t-1}^{*}\right)}{\Delta\left(g, g^{\prime}\right)}-C_{s, g, t-1}\right)$. The black line gives the biomass distribution across 10 grid cells on a line at time $t$ (high to low biomass gradient from left to right opposite to the growth rate gradient). The biomass distribution for different values of $V_{s}$ at the following time step $t+1$ is shown in colour. 

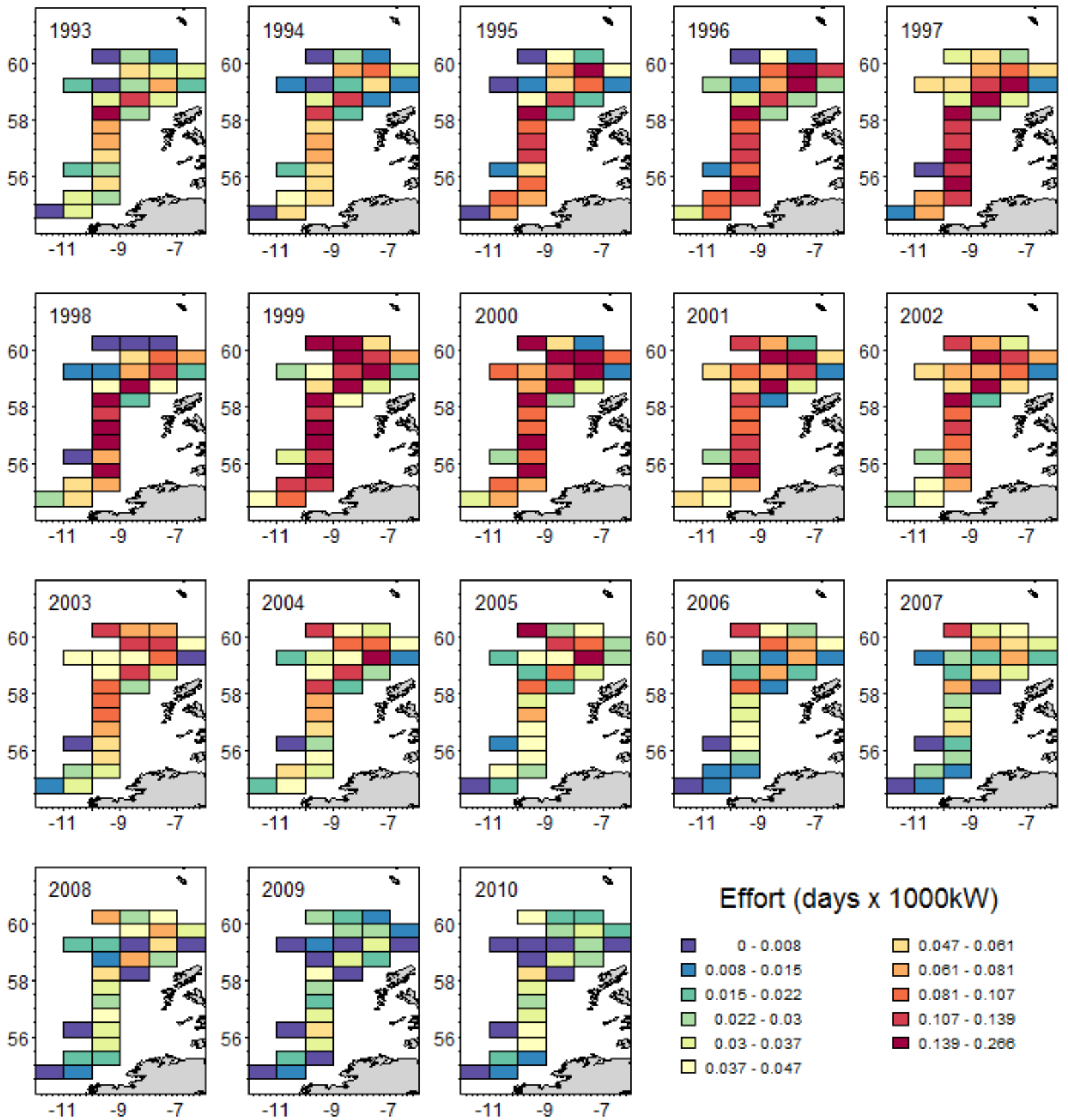

Fig. S2. Spatial distribution of French fishing effort (days trawling $\times$ vessel power) from logbook data. All maps are on the same percentile scale.

\section{References}

Augustin N.H., Trenkel V.M., Wood S.N., Lorance P., 2013, Spacetime modelling of blue ling for fisheries stock management. Environmetrics 24 109-119.

Blanchard J.L., Maxwell D.L., Jennings S., 2008, Power of monitoring surveys to detect abundance trends in depleted populations: the effects of density-dependent habitat use, patchiness, and climate change. ICES J. Mar. Sci. 65, 111-120.

Blanchard J.L., Mills C., Jennings S., Fox C.J., Rackham B.D., Eastwood P.D., O'Brien C.M., 2005, Distribution-abundance relationships for North Sea Atlantic cod (Gadus morhua): observation versus theory. Can. J. Fish. Aquat. Sci. 62, 2001-2009.
Brown J.H., Maurer B.A., 1989, Macroecology: the division of food and space among species on continents. Science 243, 1145-1150.

Diggle P.J., Menezes R., 2010, Geostatistical inference under preferential sampling. Appl. Stat. 59, 191-232.

EC, 2008, Directive 2008/56/EC of the European Parliament and of the Council of 17 June 2008 establishing a framework for community action in the field of marine environment policy (Marine Strategy Framework Directive. Off. J. Eur. Union 25.6.2008 L164, 19-40.

EC, 2010, Commission Decision of 1 September 2010 on criteria and methodological standards on good environmental status of marine waters. Off. J. Eur. Union 2.9.2010 L 232, 14-24.

Ehrich S., 1983, On the occurrence of some fish species at the slopes of the Rockall Trough. Arch. Fisch. 33, 105-150. 
Fisher J.A.D., Frank K.T., 2004, Abundance-distribution relationships and conservation of exploited marine fishes. Mar. Ecol. Prog. Ser. 279, 201-213.

Fretwell S.D., Lucas H.L., 1969, On territorial behaviour and other factors influencing habitat distribution in birds. Acta Biotheor. 19, 16-37.

Frisk M.G., Duplisea D.E., Trenkel V.M., 2011, Exploring the abundance-occupancy relationships for the Georges Bank finfish and shellfish community from 1963-2006. Ecol. Appl. 21, 227-240.

Gaston K.J., Blackburn T.M., Greenwood J.J.D., Gregory R.D., Quinn R.M., Lawton J.H., 2000, Abundance-occupancy relationships. J. Appl. Anim. Ecol. 37, 39-59.

Gaston K.J., Fuller R.A., 2009, The sizes of species' geographic ranges. J. Appl. Ecol. 46, 1-9.

Gelfand A.E., Sahu S.K., Holland D.M., 2012, On the effect of preferential sampling in spatial prediction. Environmentrics 23, 565-578.

Gillis D.M., Peterman R.M., 1998, Implications of interference among fishing vessels and the ideal free distribution to the interpretation of CPUE. Can. J. Fish. Aquat. Sci. 55, 37-46.

Gillis D.M., Peterman R.M., Tyler A.V., 1993, Movement dynamics in a fishery: application of the ideal free distribution to spatial allocation of effort. Can. J. Fish. Aquat. Sci. 50, 323-333.

Gillis D.M., van der Lee A., 2012, Advancing application of the ideal free distribution to spatial models of fishing effort: the isodar approach. Can. J. Fish. Aquat. Sci. 69, 1610-1620.

Harley S.J., Myers R.A., Dunn A., 2001, Is catch-per-unit-effort proportional to abundance? Can. J. Fish. Aquat. Sci. 58, 1760-1772.

Hilborn R., 2007, Defining success in fisheries and conflicts in objectives. Mar. Policy 31, 153-158.

Hilborn R., Walters C.J., 1992, Quantitative fisheries stock assessment: choice, dynamics and uncertainty. New York, Chapman and Hall.

Hutton T., Mardle S., Pascoe S., Clark R.A., 2004, Modelling fishing location choice within mixed fisheries: English North Sea beam trawlers in 2000 and 2001. ICES J. Mar. Sci. 61, 1443-1452.

Large P.A., Agnew D.J., Pérez J.Á.Á., Froján C.B., Cloete R., Damalas D., Dransfeld L., Edwards C.T.T., Feist S., Figueiredo I., González F., Herrera J.G., Kenny A., Jakobsdóttir K., Longshaw M., Lorance P., Marchal P., Mytilineou C., Planque B., Politou C.-Y., 2013, Strengths and weaknesses of the management and monitoring of deep-water stocks, fisheries and ecosystems in various areas of the world - A roadmap toward sustainable deepwater fisheries in the Northeast Atlantic? Rev. Fish. Sci. 21, $157-180$

Large P.A., Diez G., Drewery J., Laurans M., Pilling G.M., Reid D.G., Reinert J., South A.B., Vinnichenko V.I., 2010, Spatial and temporal distribution of spawning aggregations of blue ling (Molva dypterygia) west and northwest of the British Isles. ICES J. Mar. Sci. 76, 494-501.
Lorance P., Agnarsson S., Damalas D., des Clers S., Figueiredo I., Gil J., Trenkel V.M., 2011, Using qualitative and quantitative stakeholder knowledge: examples from European deep-water fisheries. ICES J. Mar. Sci. 68, 1815-1824.

Lorance P., Dupouy H., 2001, CPUE abundance indices of the main target species of the French deep-water fishery in ICES Sub-areas V-VII. Fish. Res. 51, 137-149.

Lorance P., Large P.A., Bergstad O.A., Gordon J.D.M., 2008, Grenadiers of the NE Atlantic - distribution, biology, fisheries and their impacts, and developments in stock assessment and management. In: Orlov A., Iwamoto T. (Eds.), Grenadiers of the world oceans: biology, stock assessment and fisheries. Bethesda, MS. Am. Fish. Soc. Symp. 63, 365-397.

Lorance P., Pawlowski L., Trenkel V.M., 2010, Standardizing blue ling landings per unit effort from industry haul-by-haul data using generalized additive models. ICES J. Mar. Sci. 67, 1650-1658

Lorance P., Trenkel V.M., 2006, Variability in natural behaviour, and observed reactions to an ROV, by mid-slope fish species. J. Mar. Exp. Biol. Ecol. 332, 106-119.

MacCall A.D., 1990, Dynamic geography of marine fish populations. Seattle, WA, University of Washington Press.

Mauchline J., Gordon J.D.M., 1983, Diets of the sharks and chimaeroids of the Rockall Trough, northeastern Atlantic Ocean. Mar. Biol. 75, 269-278.

Mauchline J., Gordon J.D.M., 1984, Diets and bathymetric distributions of the macrourid fish of the Rockall Trough, northeastern Atlantic Ocean. Mar. Biol. 81, 107-121.

Murawski S.A., Wigley S.E., Fogarty M.J., Rago P.J., Mountain D.G., 2005, Effort distribution and catch patterns adjacent to temperate MPAs. ICES J. Mar. Sci. 62, 1150-1167.

Murray L.G., Hinz H., Kaiser M.J., 2011, Functional response of fishers in the Isle of Man scallop fishery. Mar. Ecol. Prog. Ser. 430, $157-169$.

Neves A., Vieira A.R., Farias I., Figueiredo I., Sequeira V., Gordo L.S., 2009, Reproductive strategies in black scabbardfish (Aphanopus carbo Lowe, 1839) from the NE Atlantic. Scient. Mar.73, 19-31.

Paloheimo J.E., Dickie L.M., 1964, Abundance and fishing success. Rapp. P.-V. Réun. Cons. Int. Explor. Mer 155, 152-163.

Schaeffer M.B., 1954, Some aspects of the dynamics of populations important to the management of the commercial marine fisheries. Inter-Am. Trop. Tuna Comm. Bull. 1, 23-56.

Shackell N.L., Frank K.T., Brickman D.W., 2005, Range contraction may not always predict core areas: an example from marine fish. Ecol. Appl. 15, 1440-1449.

Swain D.P., Sinclair A.F., 1994, Fish distribution and catchability: What is the appropriate measure of distribution? Can. J. Fish. Aquat. Sci. 51, 1046-1054.

Wilberg M.J., Thorson J.T., Linton B.C., Berkson J., 2010, Incorporating time-varying catchability into population dynamics stock assessment models. Rev. Fish. Sci. 18, 7-24. 